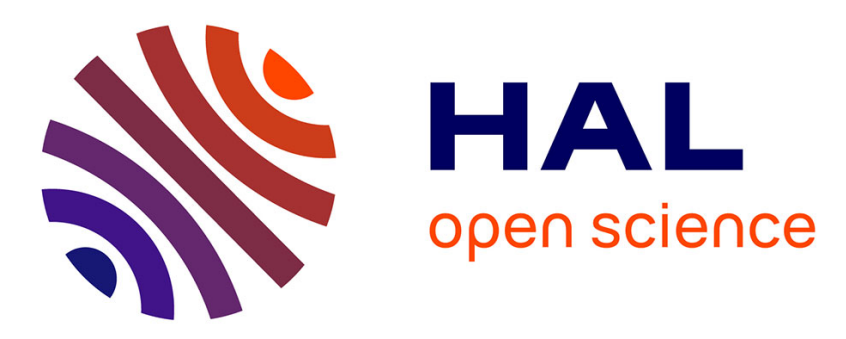

\title{
Antibody-Based Detection of Global Nuclear DNA Methylation in Cells, Tissue Sections, and Mammalian Embryos
}

Nathalie Beaujean, Juliette Salvaing, Nur Annies Abd Hadi, Sari Pennings

\section{- To cite this version:}

Nathalie Beaujean, Juliette Salvaing, Nur Annies Abd Hadi, Sari Pennings. Antibody-Based Detection of Global Nuclear DNA Methylation in Cells, Tissue Sections, and Mammalian Embryos. Tost J. DNA Methylation Protocols. Series Methods in Molecular Biology, 1708 (3ème ed), Humana Press, NY, pp.59-80, 2018, Methods in Molecular Biology, 1064-3745. 10.1007/978-1-4939-7481-8_4 . hal02238169

\section{HAL Id: hal-02238169 \\ https://hal.science/hal-02238169}

Submitted on 20 May 2020

HAL is a multi-disciplinary open access archive for the deposit and dissemination of scientific research documents, whether they are published or not. The documents may come from teaching and research institutions in France or abroad, or from public or private research centers.
L'archive ouverte pluridisciplinaire HAL, est destinée au dépôt et à la diffusion de documents scientifiques de niveau recherche, publiés ou non, émanant des établissements d'enseignement et de recherche français ou étrangers, des laboratoires publics ou privés. 
Antibody-Based Detection of Global Nuclear DNA Methylation in Cells, Tissue Sections, and Mammalian Embryos

Nathalie Beaujean ${ }^{1,2}$ Email: nathalie.beaujean@inserm.fr

Juliette Salvaing ${ }^{1}$

Nur Annies Abd Hadi ${ }^{3}$

Sari Pennings ${ }^{3} \bowtie$ Email: Sari.Pennings@ed.ac.uk

${ }^{1}$ INRA, UMR1198 Biologie du Développement et Reproduction, 78350 Jouy-en-Josas France

${ }^{2}$ Univ Lyon, Université Claude Bernard Lyon 1, Inserm, INRA, Stem Cell and Brain Research Institute U1208, USC1361, 69500 Bron France

${ }^{3}$ Centre for Cardiovascular Science, Queen's Medical Research Institute, University of Edinburgh, Edinburgh EH16 4TJ United Kingdom

\section{Abstract}

Immunostaining is widely used in cell biology for the in situ detection of proteins in fixed cells. The method is based on the specificity of antibodies for recognizing and binding to a selected target, combined with immunolabeling techniques for microscopic imaging. Antibodies with high specificities for modified nucleotides have also been widely developed, and among those, antibodies that recognize modified cytosine: 5-methylcytosine $(5 \mathrm{mC})$, and more recently, its derivates 5hydroxymethylcytosine $(5 \mathrm{hmC}), 5$-formylcytosine $(5 \mathrm{fC})$ and 5 -carboxylcytosine $(5 \mathrm{caC})$. To allow for their detection, primary antibody signals can be amplified using secondary antibodies coupled to fluorophores for immunofluorescence, or other molecules for immunocytochemistry.

Immunostaining can be used to gain information on the spatial distribution and levels of DNA methylation states within the nucleus. Although the resolution remains quite low in genomic terms, advanced microscopy techniques and image analysis can obtain detailed spatial information content from immunostained sites. The technique complements genomic approaches that permit the assessment of DNA methylation on specific sequences, but that cannot provide global nuclear spatial context. Immunostaining is an accessible method of great benefit in several cases: when working with limited material (such as embryos or primary cells), to quickly assess at the level of individual cells the effect of siRNA, drugs, or biological processes that promote or inhibit DNA methylation or demethylation, or to study the 3D nuclear organization of regions with high DNA methylation, such as constitutive heterochromatin. Here, we review and outline protocols for the fluorescent and enzymatic immunodetection of DNA methylation in the nuclei of cells, tissue sections, and mammalian embryos. 


\section{Introduction}

\subsection{Epigenetic Modifications of DNA, Localization, and Function}

DNA methylation in mammalian genomes occurs primarily at $\mathrm{CpG}$ dinucleotide sequences, most of which are found in a methylated $\mathrm{meCpG}$ state carrying 5-methylcytosine $(5 \mathrm{mC})$. This primary form of DNA methylation has been linked to silencing of repetitive elements, genomic imprinting, and $\mathrm{X}$ chromosome inactivation. In addition, the propagation of stable gene repression patterns in cell types is commonly attributed to the epigenetic heritability of $\mathrm{meCpG}$, which is maintained through DNA replication by DNA methyltransferases (DNMTs) [12]. DNA methylation may coordinately modulate chromatin states with histone modifications via interactions between modifying enzymes and methyl binding domains [23]. Silencing of genes or genomic regions by DNA methylation is associated with the repressive compartment of the nucleus [4]. Epigenetic states are set up in early embryos [56]; however, highly condensed constitutive heterochromatin does not acquire a mature histone modification signature until late in development [7]. Other less abundant forms of DNA methylation, such as 5-hydroxymethylcytosine $(5 \mathrm{hmC})$, and the more recently identified rarer forms 5formylcytosine $(5 \mathrm{fC})$ and 5-carboxylcytosine $(5 \mathrm{CaC})$ have been linked with DNA demethylation pathways during development [8]. $5 \mathrm{hmC}$ is thought to arise as an oxidation intermediate of $5 \mathrm{mC}$ in an iterative oxidation process mediated by the TET family of enzymes [8]. Its genomic distribution pattern is nevertheless different from $5 \mathrm{mC}$, as $5 \mathrm{hmC}$ maps to the body of transcribed genes and enhancers and is a more dynamic epigenetic mark [91011]. The current focus on genomic DNA methylation mapping has driven the development of new methodologies for detecting and localizing $5 \mathrm{hmC}$ by DNA sequencing [812]. In addition, existing $5 \mathrm{mC}$ data sets have been reported to require re-evaluation after it emerged that some of the traditional $5 \mathrm{mC}$ mapping methods such as bisulfite sequencing and methylation-specific restriction analysis cannot differentiate between $5 \mathrm{mC}$ and $5 \mathrm{hmC}$ [13]. While newer chemical modification-assisted sequencing and subtraction methods offer singlebase resolution of $5 \mathrm{hmC}$ and $5 \mathrm{mC}$ (see also Chapters 33 and 34 ), whole genome coverage is currently limiting due to the higher sequencing depth required for mapping $5 \mathrm{hmC}$ [8]. For this reason, affinity-based enrichment sequencing techniques based on methylated DNA immunoprecipitation (MeDIP and hMeDIP, see also Chapters 11 and 33 ) remain a standard methodology for genome mapping. These data sets have no retrospective issues, as they rely on immunoprecipitation grade antibodies with recognized specific affinity for either $5 \mathrm{mC}$ or $5 \mathrm{hmC}$. The same antibodies can also be used for immunofluorescence microscopy detection of these epitopes in the nuclei of fixed cells, and were in several cases originally developed for this purpose.

\subsection{Antibodies for Immunodetection of DNA Methylation}

A mouse monoclonal antibody (clone 33D3) specifically recognizing $5 \mathrm{mC}$ was originally developed by Alain Niveleau for the detection of methylnucleosides in enzyme-linked immunoassays [14]. It was 
subsequently validated for microscopic visualization of methylcytosine-rich DNA on metaphase chromosomes and in thin sections from paraffin -embedded cancer tissue [1516]. Several other applications have predominantly relied on this antibody, including MeDIP [17] (see also Chapter 11 ). The monoclonal mouse IgG1 $\lambda$ clone $33 \mathrm{D} 3$ is still the most cited antibody and is commercially available from several sources. More recently marketed monoclonal antibodies include clone 10G4 (mouse IgG1); clone MAb-006 (mouse IgG1); clone A1 (mouse IgG1); clone 87G31 (mouse IgG3א); clone 5MC-CD (mouse IgM); clone EP4694 (rabbit IgG); and others. Alternative substitutes for mouse IgG are polyclonal antibodies raised in rabbit or sheep. It is worthwhile testing antibodies, which may have different affinities for the epitope or its context, having been raised against different hapten-carrier constructs. The $5 \mathrm{mC}$ epitope may not be a strong immunogen due to its ubiquity in vertebrates. By contrast, the genome-wide abundance of $5 \mathrm{hmC}$ is an order of magnitude lower than that of $5 \mathrm{mC}[8]$. The higher affinity $5 \mathrm{hmC}$ antibodies are a boon to immunostaining procedures for microscopy, as they can be combined with $5 \mathrm{mC}$ monoclonal antibodies to visualize both signals in similar experimental conditions. As a precaution, preliminary single and double immunostaining experiments should be performed to check that the antibodies are not physically cross-reacting when both marks are found in the vicinity of each other [18]. The market for $5 \mathrm{hmC}$ antibodies is still expanding; therefore, recent citations are a good guide. Polyclonal antibodies are frequently used to allow simultaneous anti-rabbit/anti-mouse secondary antibody immunofluorescence detection of $5 \mathrm{hmC} / 5 \mathrm{mC}$. Monoclonal antibodies are also available: clone HMC 31 (mouse IgG1 $\kappa$ ); clone HMC-

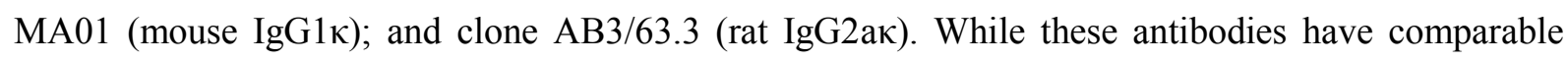
specificities, rabbit polyclonal $5 \mathrm{hmC}$ antibody was reported to have a slightly higher immunoprecipitation efficiency, as well as higher dot blot efficiency, as compared with rat monoclonal antibody [1920]. Rabbit polyclonal 5-caC antibodies and 5-fC antibodies originally generated for immunostaining are now also available [21].

\subsection{General Considerations in Antibody-Based Detection}

Several steps are critical when performing immunostaining. First is the fixation : this step is meant to kill the cell while preserving it as much as possible in its original state. The main fixatives used are alcohols (e.g., methanol or a mixture of ethanol and acetic acid) or aldehydes (para/formaldehyde and glutaraldehyde ). These have different effects on the cell; therefore, the choice of the fixative depends on the question addressed and on the antigen of interest. One of the major effects of alcohol-based fixatives is dehydration of the cell. As such, they affect the 3D organization of the cell/ nucleus , which is why they are not a primary choice for our studies. On the other hand, paraformaldehyde is effective for the fixation of nucleic acids and allows better preservation of the 3D structure. Other parameters, such as length of fixation and concentration of the fixative, can also play an important role. Indeed, a weak fixation can result in protein degradation, whereas a strong fixation can alter the 
structure of protein antigens and their subsequent recognition by antibodies. A second important step is the permeabilization of the cells, as antibodies are large molecules that cannot naturally enter the cells. Alcoholic fixatives extract the cell lipids and thus do not necessitate additional permeabilization treatment, but this is not the case with paraformaldehyde. Permeabilization is performed using detergents, most often Triton X-100, but also Tween 20, NP-40, or other. Insufficient permeabilization will result in poor signal quality due to the lack of penetration of the antibodies, whereas overtreatment can have dramatic effects on cell morphology.

\subsection{DNA Methylation Immunocytochemistry on Cells}

Antibodies raised against the 5-methylcytosine group and its derivatives have in most cases selective affinity for these epitopes on denatured DNA strands. Whereas genomic DNA immunoprecipitation or immunodetection is performed on isolated DNA, immunocytochemistry aims to visualize these epitopes in their cell nuclear context. DNA denaturation of samples can retain cell morphology, yet it is often incompatible with quantitative co- staining for protein components of the cell. The additional DNA denaturation step requires additional time and skills compared to standard immunostaining protocols. Incomplete denaturation may result in weak and uneven staining of nuclei, whereas excess denaturation will eventually damage the DNA, with similar outcomes. Before embarking on a new type of sample, whether cells, tissues, or whole embryo , an initial denaturation test series is strongly advisable in order to determine optimal conditions for DNA methylation staining. A second point of consideration is the avidity of $5 \mathrm{mC}$ epitopes and their derivatives in genomic DNA, given their variable local frequency in the DNA sequence. The avidity stems from the multiplicity of affinities in sequences where a higher local concentration of single-binding sites exists. This results in different functional affinities of the antibody for sites of high density versus low density of DNA methylation. Binding saturation, as with overnight antibody incubation, is generally avoided in order to report on the dynamic range of DNA methylation densities and to visualize the densely $5 \mathrm{mC}$ methylated heterochromatin in particular. On the other hand, long incubation may provide a general overview of all the genomic regions bearing $5 \mathrm{mC}$, allowing their localization in the nuclei.

\subsection{DNA Methylation Immunohistochemistry on Tissue Sections}

Standard histological analysis involves tissue fixation and dehydration followed by embedding in paraffin . Archived clinical samples, for example, are assayed in human tissue microarrays or whole tissue blocks, from which paraffin thin sections can be cut on a microtome as required. Immunohistochemistry on paraffin sections requires rehydration and antigen retrieval steps. While this methodology uniquely permits the analysis of archival samples, the organic solvent treatments affect cell morphology, which is best viewed at lower magnification. They may also reduce the epitope yield for immunostaining —although this is less an issue for DNA than for protein epitopes. Immunofluorescence staining of animal tissues is often performed on frozen tissue cryosections . 
These tissues are fresh frozen and embedded in aqueous mounting medium to facilitate cryosectioning. This method uses paraformaldehyde (PFA) as the sole fixative and generally aims to preserve native protein epitopes in their original cell morphology. Identification of the tissue context is less straightforward than on paraffin sections, however; this may require counterstaining of alternate sections. Blocks can be stored frozen but cryosections are generally best processed without further freezing/defrosting. DNA methylation antibodies have been shown to work in either of these fixative and preparative conditions. DNA methylation immunohistochemistry on tissue sections is nevertheless less commonly performed than immunocytochemistry on cultured cells or whole mount embryos. One issue is that thin sections are dense in extracellular as well as cellular material compared to cultured cells and thus produce more background signal. More importantly, a survey of the literature to date shows uneven results for DNA methylation staining of nuclei in tissue sections and immunofluorescence staining of cryosections in particular. After testing several protocol variations from the literature, we have narrowed this problem down to a difficulty in achieving DNA denaturation in cryosections when relying on the $\mathrm{HCl}$ denaturation step of immunocytochemistry protocols. Of particular concern was that even when DNA denaturation did not take place, as evidenced by a lack of reduction in DAPI fluorescence, acid treatment often resulted in a high nonspecific nuclear background. This staining was similar with all DNA antibodies but dissimilar from the DAPI stained DNA pattern. At low magnification this could be mistaken (and was in a few instances reported) as a nuclear signal, but it was revealed at higher resolution to consist of aggregates. By contrast, other reports that employed the immunocytochemistry protocol for cryosections showed partial, mosaic nuclear staining for DNA methylation in some tissues. We observed similar mosaic results following longer $\mathrm{HCl}$ treatment and overnight antibody incubation but found that these apparently partial results could not be improved further. As none of these issues are encountered with whole mount staining of tissues, we reasoned that DNA denaturation by boiling in sodium citrate buffer, as used in Southern hybridization and FISH methodology, might be more effective on substrate-bound dehydrated DNA, including DNA in sections adhered onto glass. Furthermore, in immunohistochemistry this step serves as an antigen retrieval method by breaking fixative crosslinks, aiding the process. The original paraffin section $5 \mathrm{mC}$ staining protocol, also presented here, combines a sodium citrate boiling step with $\mathrm{HCl}$ denaturation [16]. Furthermore, the Pfeifer lab with experience in both clinical paraffin and cryosections employed a hybrid protocol for the latter in a rare demonstration of reliable DNA methylation staining [22]. For cryosections, we therefore do not recommend $\mathrm{HCl}$ treatment for DNA denaturation and present a sodium citrate boiling step protocol that we recently developed in our lab. 


\subsection{DNA Methylation Immunocytochemistry on Whole Mount Embryos}

Immunofluorescence imaging techniques are widely used in the study of mammalian embryos, which due to their size, transparency, and low cell number are particularly suitable to microscopic methods . During the first stages of development, the genome of the embryos is silent, and development is sustained by maternally inherited RNA and proteins, which have accumulated during oogenesis. Thus, the zygote (1-cell embryo ) is a huge cell with a very large cytoplasm, and even in the subsequent cleavage stages, the size of the cells remains large. This provides a challenge for immunostaining, as penetration of antibodies into the nucleus is more difficult in embryos than in most cell types. As a result, conditions for fixation and permeabilization may differ from what is typically used for cells, and overnight incubations with primary antibodies are usually preferable to short incubations. Antibody concentrations are also generally slightly increased; in some cases, antibodies with a low affinity that still give a signal in regular cells do not perform in embryos, even though their target is present. It must be noted that in the first developmental stages, and in particular in the zygote, nuclei are very decondensed, which can hinder the detection of low density nuclear antigens. As discussed previously, the $5 \mathrm{mC}$ epitopes in the DNA need to be exposed so the antibodies can bind to their target. This requires DNA denaturation, which in embryos is commonly performed using $\mathrm{HCl}$. The conditions for $\mathrm{HCl}$ denaturation, concentration, incubation temperature, and time are again very important to test [18]. Tryptic digestion, which digests the proteins binding to $5 \mathrm{mC}$, can also be used in addition to $\mathrm{HCl}$ to achieve valid measurements of immunolocalizations [23, 24]. 


\section{Materials}

\subsection{DNA Methylation Immunocytochemistry on Cells}

1. Tissue culture hood and $\mathrm{CO}_{2}$ incubator; aspirator.

2. Cell culture plates: 24-well or 6-well.

3. Cell culture media; gelatine solution.

4. Phosphate-buffered saline "Dulbecco A" (PBS): $137 \mathrm{mM} \mathrm{NaCl}, 2.7 \mathrm{mM} \mathrm{KCl}, 8.1 \mathrm{mM} \mathrm{Na} 2 \mathrm{HPO}_{4}$, $1.5 \mathrm{mM} \mathrm{KH}_{2} \mathrm{PO}_{4}$ (supplemented with $1 \mathrm{mM} \mathrm{CaCl}_{2}$ for washing of cell cultures).

5. 4\% Paraformaldehyde (PFA) in PBS.

6. $0.4 \%$ Triton $\mathrm{X}-100$ in PBS.

7. PBST buffer: $0.2 \%$ Tween 20 in PBS.

8. $4 \mathrm{M}$ Hydrochloric acid (HCl).

9. Blocking buffer: $2 \%$ BSA and (optional) 1\% donkey serum in PBS.

10. Primary and secondary antibodies (see Notes 1 and 2).

11. DNA counterstain stock solution: $3 \mathrm{mM} \mathrm{4',6-diamidino-2-phenylindole} \mathrm{(DAPI).}$

12. Mounting medium (see Note 3 ).

13. Cover slips No. 1.5; sizes $13 \mathrm{~mm}$ round (24-well plate); $22 \mathrm{~mm}$ square (6-well plate) (see Note 4).

14. Microscope carrier slides.

\subsection{DNA Methylation Immunohistochemistry on Paraffin-Embedded Tissues}

1. Microtome.

2. Superfrost Plus adhesion microscope slides; cover slips.

3. Histology staining baths with glass slide holders.

4. Plastic Coplin jar.

5. Microwave oven.

6. Hydrophobic barrier PAP pen.

7. Humidity chamber.

8. Deionized water $\left(\mathrm{H}_{2} \mathrm{O}\right)$.

9. Tris- $\mathrm{HCl}$ buffer: $50 \mathrm{mM}$ Tris-HCl, $150 \mathrm{mM} \mathrm{NaCl}, 0.01 \%$ Triton $\mathrm{X}-100, \mathrm{pH}$ 7.6.

10. Phosphate-buffered saline (PBS): $137 \mathrm{mM} \mathrm{NaCl}, 2.7 \mathrm{mM} \mathrm{KCl}, 8.1 \mathrm{mM} \mathrm{Na} \mathrm{HPO}_{4}, 1.5 \mathrm{mM}$ $\mathrm{KH}_{2} \mathrm{PO}_{4}$.

11. PBE buffer: $1 \%$ BSA (fraction V), 1 mM EDTA in PBS.

12. $0.01 \mathrm{M}$ Citric acid, adjusted with $1 \mathrm{M}$ sodium hydroxide to $\mathrm{pH} 6.0$ (or made up as $0.01 \mathrm{M}$ sodium citrate buffer, $\mathrm{pH}$ 6.0).

13. 3.5 M Hydrochloric acid ( $\mathrm{HCl})$.

14. $3 \%$ Hydrogen peroxide $\left(\mathrm{H}_{2} \mathrm{O}_{2}\right)$.

15. $1 \%$ Goat serum (or other to match secondary antibody host).

16. Primary and secondary antibodies (see Notes 1 and 2). 
17. Biotin-streptavidin peroxidase-based detection system.

18. Chromogen substrate (3,3'-diaminobenzidine tetrahydrochloride (DAB) or other).

19. Hematoxylin counterstain.

\subsection{DNA Methylation Immunohistochemistry on Cryosections}

1. Cryotome.

2. Superfrost Plus adhesion microscope

slides; cover slips.

3. Schieferdecker jar (or heat resistant beaker with glass slide holder).

4. Microwave and microwave dish (or hotplate for heating beaker).

5. Hydrophobic barrier PAP pen.

6. Humidity chamber.

7. Phosphate-buffered saline (PBS): $137 \mathrm{mM} \mathrm{NaCl}, 2.7 \mathrm{mM} \mathrm{KCl}, 8.1 \mathrm{mM} \mathrm{Na} \mathrm{HPO}_{4}, 1.5 \mathrm{mM}$ $\mathrm{KH}_{2} \mathrm{PO}_{4}$.

8. $2 \%$ Paraformaldehyde (PFA) in PBS.

9. $0.5 \%$ Triton $\mathrm{X}-100$ in PBS.

10. PBST buffer: $0.2 \%$ Tween 20 in PBS.

11. $0.01 \mathrm{M}$ Citric acid adjusted with $1 \mathrm{M}$ sodium hydroxide to $\mathrm{pH} 6.0$ (or made up as $0.01 \mathrm{M}$ sodium citrate buffer, $\mathrm{pH}$ 6.0).

12. Blocking buffer: 2\% BSA and (optional) 1\% donkey serum in PBS.

13. Primary and secondary antibodies (see Notes 1 and 2).

14. DNA counterstain stock solution: $3 \mathrm{mM}$ 4',6-diamidino-2-phenylindole (DAPI).

15. Mounting medium (see Note 3).

\subsection{For DNA Methylation Immunocytochemistry on Whole Mount Embryos}

Prepare all the solutions using ultrapure water $\left(18.2 \mathrm{M} \Omega \mathrm{cm}\right.$ resistivity at $\left.25^{\circ} \mathrm{C}\right)$.

1. Fixative: $20 \%$ paraformaldehyde (PFA) solution. Upon opening of the stock solution, adjust $\mathrm{pH}$ to $\sim 7.0$ with $0.2 \mathrm{M} \mathrm{NaOH}$ if necessary and store maximum for 1 month at $4{ }^{\circ} \mathrm{C}$ with light protection (aluminum foil for example). Before each experiment, $\mathrm{pH}$ should be checked with a $\mathrm{pH}$ indicator strip; discard if below $\mathrm{pH} 7.0$ or above $\mathrm{pH}$ 7.4.

2. Phosphate-Buffered Saline (PBS): $137 \mathrm{mM} \mathrm{NaCl}, 2.7 \mathrm{mM} \mathrm{KCl}, 8.1 \mathrm{mM} \mathrm{Na}_{2} \mathrm{HPO}_{4}, 1.5 \mathrm{mM}$ $\mathrm{KH}_{2} \mathrm{PO}_{4}$. We usually prepare PBS by dissolving commercially available tablets in deionized water according to the manufacturer's instructions, autoclave and store at $4{ }^{\circ} \mathrm{C}$. Filter through a $0.22 \mu \mathrm{m}$ sterile cellulose acetate membrane before use.

3. Permeabilization stock solution: prepare $10 \%$ Triton X-100 stock solution with ultrapure water $(\mathrm{w} / \mathrm{v})$ and mix slowly to avoid bubbles. We recommend storage at $4{ }^{\circ} \mathrm{C}$ for maximum 1 month.

4. PBS-BSA $2 \%$ solution: dissolve BSA powder slowly in PBS (w/v) and filter through $0.22 \mu \mathrm{m}$ sterile cellulose acetate membranes. Aliquots of 1 or $2 \mathrm{~mL}$ can be kept at $-20^{\circ} \mathrm{C}$ for several months 
and thawed just before use. After thawing, filter through a $0.22 \mu \mathrm{m}$ sterile cellulose acetate membrane, store at $4{ }^{\circ} \mathrm{C}$.

5. Concentrated Hydrochloric acid ( $\mathrm{HCl} 37 \%)$.

6. Primary and secondary antibodies (see Notes 1 and 2).

7. Mineral oil, embryo tested: keep at room temperature and protect from direct light.

8. Nucleic acid stain (see Note 5).

9. Mounting antifading medium and clear nail polish.

10. Dissecting microscope with appropriate working distance and heating block set at $27^{\circ} \mathrm{C}$ (see Note $6)$.

11. Aspirator tube ( $40 \mathrm{~cm}$ length) and thin glass pipettes for embryo manipulation (see Note 7 ).

12. Embryo glass dishes with glass lids and parafilm to secure the lids (see Note 8).

13. Petri dishes ( 35 or $60 \mathrm{~mm}$ diameter); micro test tubes ( 0.5 or $1.5 \mathrm{~mL}$ ).

14. $37^{\circ} \mathrm{C}$ oven or incubator.

15. SuperFrost Plus slides and glass cover slips (see Note 9). 


\section{Methods}

\subsection{DNA Methylation Immunocytochemistry on Cells}

The cell immunostaining protocol outlined below is widely used in the field, with minor variations (see Note 10).

1. Grow the cells on gelatine-coated No. 1.5 glass cover slips inside a multi-well culture plate.

2. Remove the medium by washing cells twice in PBS containing $1 \mathrm{mM} \mathrm{CaCl}_{2}$ (5 min each). Remove solutions by aspiration. Do not let the cells dry during the following steps performed at room temperature.

3. Add $200 \mu \mathrm{L}$ of $4 \%$ PFA in PBS to each cover slip (13 mm diameter) for $10 \mathrm{~min}$ to fix cells. Remove the fixation solution and rinse cells twice in $200 \mu \mathrm{L}$ of PBS (5 min each).

4. Add $200 \mu \mathrm{L}$ of $0.4 \%$ Triton X-100 in PBS to each cover slip for 15 min to permeabilize cells. Remove the permeabilization solution and rinse the cells twice in PBS (10 min each).

5. Add $200 \mu \mathrm{L}$ of $4 \mathrm{M} \mathrm{HCl}$ to each cover slip for $10 \mathrm{~min}$ to denature the DNA. Neutralize with $100 \mathrm{mM}$ Tris- $\mathrm{HCl} \mathrm{pH} 8.5$ (this optional neutralization step ensures reproducible conditions when multiple slides are processed). Remove the solution and rinse the cells three times in $200 \mu \mathrm{L}$ of PBS (5 min each).

6. Add $200 \mu \mathrm{L}$ of $2 \%$ BSA in PBS containing (optional) $1 \%$ donkey serum and incubate for $1 \mathrm{~h}$ to prevent nonspecific staining. Remove the blocking solution (except from those cells that will serve as the "no antibody" controls, see Note 11).

7. Add the primary antibody diluted 1:300-1:500 in the blocking solution. Incubate the cells under closed cover for $2 \mathrm{~h}$ at room temperature. Remove the antibody solution and rinse the cells three times in $200 \mu \mathrm{L}$ of PBST (15 min each), removing the solutions between each step.

8. Add the fluorescent secondary antibody diluted 1:250 in blocking solution and incubate for $1 \mathrm{~h}$ as above, in the dark. Remove the antibody solution and rinse the cells in $200 \mu \mathrm{L}$ of PBST (15 min).

9. Add $0.3 \mu \mathrm{M}$ of DAPI solution in PBST for 15 min to counterstain for DNA (denatured DNA has a reduced DAPI fluorescence; for alternative DNA staining see Note 5). Remove the counterstaining solution and rinse once with PBS (15 min).

10. Mount the cover slips onto standard microscope slides using mounting medium. Leave the slides to cure overnight at room temperature.

\subsection{DNA Methylation Immunohistochemistry on Paraffin-Embedded Tissues}

This protocol is based on standard immunohistochemistry methodology starting from formalin-fixed tissue embedded in a paraffin block. It is adapted from a protocol developed by Niveleau and colleagues for the original $5 \mathrm{mC}$ antibody [16].

\subsubsection{Preparation of Paraffin Sections and Rehydration}

1. Using a microtome, cut thin $5 \mu \mathrm{m}$ paraffin sections and adhere 1-3 sections per coated microscope slide. 
2. To remove paraffin from the sections, heat the slides in an oven for $1 \mathrm{~h}$ at $58{ }^{\circ} \mathrm{C}$. Transfer to a xylene bath with three changes of xylene ( 2 min each).

3. Rehydrate tissues by putting the slides successively through 100\%, 95\%, 75\% ethanol ( 3 min each), and finally in Tris- $\mathrm{HCl}$ buffer (3-30 min).

4. Drain excess buffer and carefully dry an area around each section using a piece of tissue, then draw a hydrophobic barrier around the sections using a PAP pen. Do not allow sections to dry from this point onward.

5. If not proceeding right away, cover the sections with 50-200 $\mu \mathrm{L}$ (depending on size) of Tris- $\mathrm{HCl}$ buffer. Place in a humidity chamber, which can keep specimens stable for a few hours.

\subsubsection{Antigen Retrieval and DNA Denaturation}

1. Drain the buffer from the slides before placing slides in a plastic Coplin jar filled with $\mathrm{H}_{2} \mathrm{O}(1-$ $3 \mathrm{~min})$.

2. Stand the jar in a wide microwave dish filled $2.5 \mathrm{~cm}$ high with $\mathrm{H}_{2} \mathrm{O}$ and heat in the microwave for 8 min until the water is near boiling point.

3. Taking great care, remove the very hot $\mathrm{H}_{2} \mathrm{O}$ from the Coplin jar and fill the jar to the top with antigen retrieval solution (0.01 $\mathrm{M}$ citric acid, $\mathrm{pH} 6.0)$.

4. Place the Coplin jar in the microwave dish containing the hot $\mathrm{H}_{2} \mathrm{O}$. Heat in the microwave oven on high power to boiling point; then continue heating to allow a further 5 min of boiling (see Note 12). Continue heating in the microwave for a further $5 \mathrm{~min}$ of boiling.

5. Carefully remove the hot Coplin jar with slides from the microwave oven and allow cooling for 10$15 \mathrm{~min}$.

6. Rinse the slides twice with $\mathrm{H}_{2} \mathrm{O}$ and transfer to $3.5 \mathrm{M} \mathrm{HCl}$ for $15 \mathrm{~min}$ to denature the DNA. Rinse again with $\mathrm{H}_{2} \mathrm{O}$ and place the slides in Tris- $\mathrm{HCl}$ buffer.

7. Drain and circumscribe sections on the slides with a hydrophobic barrier pen, as described above. Proceed without allowing the sections to dry.

\subsubsection{Immunostaining Using Peroxidase Conjugates}

1. In the preparation for peroxidase staining, quench the endogenous peroxidase activity in the sections by adding $50-200 \mu \mathrm{L}$ of $3 \% \mathrm{H}_{2} \mathrm{O}_{2}$ for $3 \mathrm{~min}$. Rinse in Tris- $\mathrm{HCl}$ buffer for $3 \mathrm{~min}$, draining the solutions from the slides between each step.

2. Arrange the slides in a humidity chamber. Add $50-200 \mu \mathrm{L}$ of $1 \%$ goat serum in PBE onto each section to prevent nonspecific staining, and incubate for $10 \mathrm{~min}$. Drain the blocking solution from the slide by gently tapping the side onto paper tissue (except from those sections that will serve as the "no antibody" control).

3. Add the primary antibody diluted in PBE buffer to the concentration recommended by the manufacturer. Incubate the slides in the humidity chamber for $1 \mathrm{~h}$ at room temperature. Rinse the slides twice in Tris- $\mathrm{HCl}$ ( 5 min each), draining the solutions between steps. 
4. Add the biotinylated secondary antibody diluted in PBE buffer. Incubate the slides in the humidity chamber for $30 \mathrm{~min}$ at room temperature. Rinse twice in Tris- $\mathrm{HCl}$ ( 5 min each) as before.

5. Add streptavidin-peroxidase diluted in PBE buffer to the slides and incubate for $30 \mathrm{~min}$ (or as indicated by the manufacturer). Rinse the slides twice in Tris- $\mathrm{HCl}$ ( 5 min each) as before.

6. Add the DAB mixture (or other substrates) to the slides and incubate until the desired intensity of staining is achieved (2-15 min). Rinse the slides with $\mathrm{H}_{2} \mathrm{O}$.

\subsubsection{Hematoxylin Counterstaining}

1. Place the slides with stained sections in Mayers hematoxylin for 1 min (less in a fresh solution; avoid overstaining). Rinse with tap water for $1 \mathrm{~min}$.

2. Depending on the enzyme substrate used: either mount the sections with cover slips using aqueous mounting medium such as glycerol gelatine; alternatively, dehydrate the slides through graded alcohols 70 ; 95 and 100\% alcohol ( 3 min each), followed by three changes of xylene; then mount cover slips using Permount or similar.

\subsection{DNA Methylation Immunohistochemistry on Cryosections}

Following comparative testing of published methods, we do not recommend using cell-based immunocytochemistry protocols for tissue cryosections (see Subheading 1 and Note 13). We outline below an alternative protocol for cryosections recently developed in our lab, in which the DNA is denatured by boiling in sodium citrate buffer. The representative results are given in Fig. 1.

1. Using a cryotome, cut 5-7 $\mu \mathrm{m}$ cryosections from fresh frozen embedded tissues and adhere 1-3 sections per coated microscope slide. Trace a hydrophobic barrier around each section using a PAP pen. Proceed with the staining procedure in a humidity chamber at room temperature. Do not allow sections to dry between steps.

2. Cover the sections with $200 \mu \mathrm{L}$ of $2 \%$ PFA in PBS for 50 min to fix the tissues. Drain the fixation solution from the slide by gently tapping the side onto paper tissue. Rinse twice with $200 \mu \mathrm{L}$ of PBS (5 min each).

3. Add $200 \mu \mathrm{L}$ of $0.5 \%$ Triton $\mathrm{X}-100$ in PBS for $30 \mathrm{~min}$ to permeabilize the tissues. Drain the permeabilization solution and rinse twice with PBS (10 min each).

4. Preheat a wide microwavable dish filled with $2.5 \mathrm{~cm}$ of $\mathrm{H}_{2} \mathrm{O}$ in a microwave oven for 8 min at full power (alternatively, preheat a heat resistant beaker containing $0.01 \mathrm{M}$ sodium citrate $\mathrm{pH} 6.0$ on a hotplate to near boiling point).

5. Fill a Schieferdecker jar with $0.01 \mathrm{M}$ sodium citrate $\mathrm{pH} 6.0$ and put the slides in. Place jar (without the lid) in the previously preheated dish, which has hot $\mathrm{H}_{2} \mathrm{O}$ in the bottom (or transfer the slides in a holder to the beaker containing preheated $0.01 \mathrm{M}$ sodium citrate $\mathrm{pH} 6.0$ ).

6. Heat the jar containing the slides in the microwave oven at full power for $3 \mathrm{~min}$ (see Note 12). Heat the slides for an additional 3 min (or bring the beaker to a boil on the hotplate, and then continue boiling for a further $10 \mathrm{~min}$ to complete DNA denaturation and antigen retrieval). 
7. Carefully remove the Schieferdecker jar from the microwave oven and allow the slides to cool for $10 \mathrm{~min}$ (or remove the beaker from the hotplate and allow the slides to cool while submerged in the solution).

8. Rinse the slides in PBS in a rocking jar for 15 min to remove any loose material.

9. Add $200 \mu \mathrm{L}$ of $2 \%$ BSA in PBS containing (optional) $1 \%$ donkey serum and incubate for $1 \mathrm{~h}$ to prevent nonspecific staining. Drain the blocking solution (except from those sections that will serve as the "no antibody" control; see Note 11).

10. Add the primary antibody diluted 1:300-1:500 in the blocking solution. Incubate the slides in the humidity chamber for $2 \mathrm{~h}$ at room temperature. Remove the antibody solution and rinse the slides three times with $200 \mu \mathrm{L}$ of PBST (15 min each), draining the solutions between each step.

11. Add the secondary antibody diluted 1:250 in blocking solution and incubate for $1 \mathrm{~h}$ as above. Remove the antibody solution and rinse the slides with $200 \mu \mathrm{L}$ of PBST (15 min).

12. Add $0.3 \mu \mathrm{M}$ of DAPI solution in PBST for 20 min to counterstain for DNA (denatured DNA has a reduced DAPI fluorescence; for alternative DNA staining see Note 5). Remove the counterstaining solution and rinse once with PBS (15 min).

13. Mount the sections with cover slips using high refractive index mounting medium. Leave the slides to cure overnight at room temperature. 
Fig. 1

Immunodetection of $5 \mathrm{mC}$ in cryosections. Cryosection of mouse E13.5 embryonic brain illustrating immunostaining protocol results for $5 \mathrm{mC}$ (upper right panel) and ssDNA (lower left panel), compared with DAPI counterstaining of DNA (upper left panel) and merged channels (lower right panel). The 5mC signal overlaps with high density DAPI nuclear foci, whereas the ssDNA signal shows a nuclear DNA pattern similar to DAPI. Antibodies (1:500 dilution) and conditions were as described in the protocol. Arrow, small unstained area for comparison; scale bar, $10 \mu \mathrm{m}$

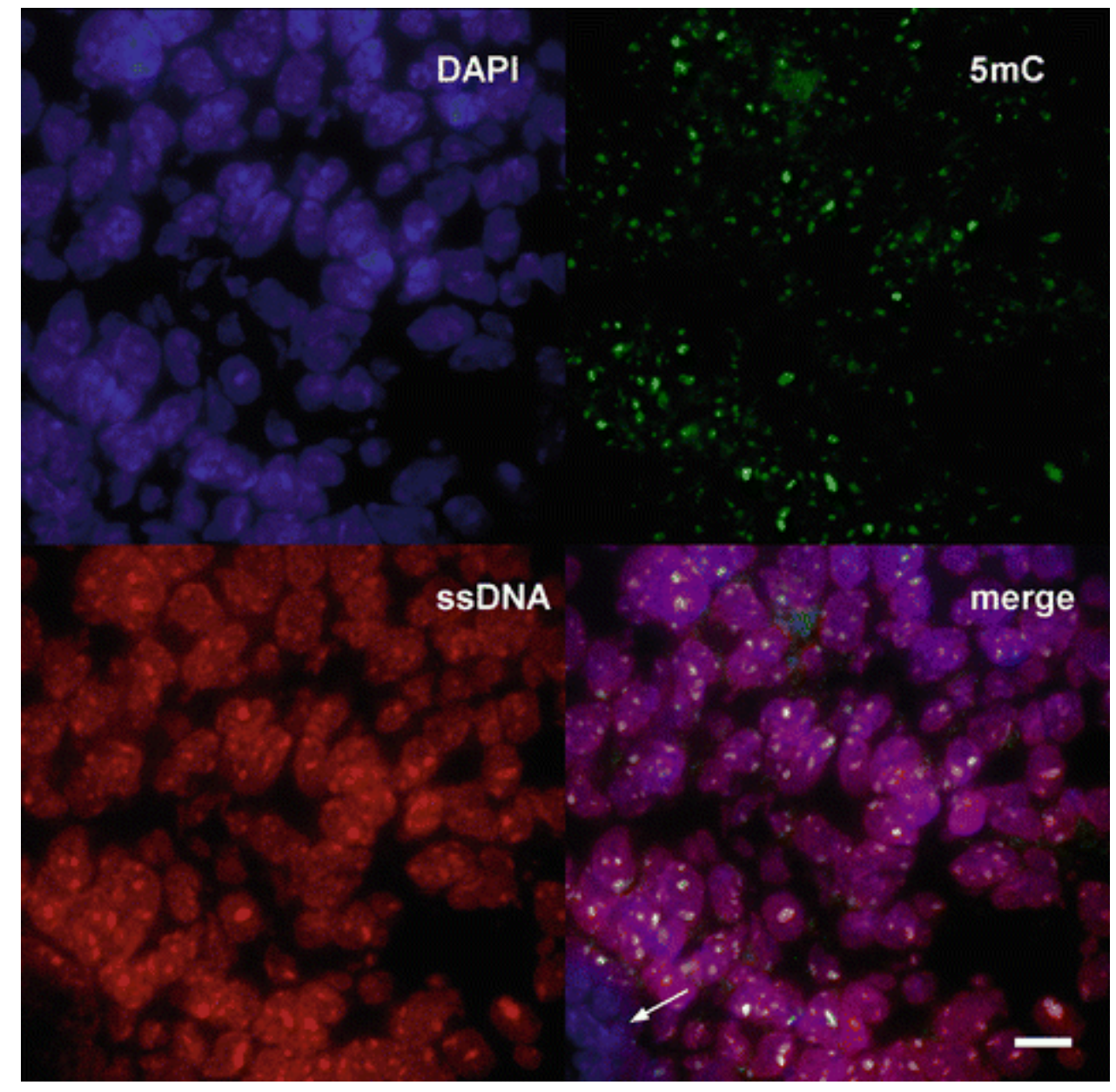




\subsection{DNA Methylation Immunocytochemistry on Whole Mount Embryos}

All the steps are performed at room temperature $\left(22-25^{\circ} \mathrm{C}\right.$ or $27{ }^{\circ} \mathrm{C}$ on the heating plate) with a total volume of $500 \mu \mathrm{L}$ per glass dish, unless otherwise mentioned. Between each step diligently follow hazardous waste recycling regulations. Carefully wash each glass dish with distilled water and dry it with a non-fluffy rag. The representative results are given in Fig. 2.

1. Label the glass dishes and lids with appropriate signs in order to identify the different groups (control, NT, etc.), date and sample size $(\mathrm{n}=\ldots)$.

2. Choose between these two modes of fixation:

Short fixation: $20 \mathrm{~min}$ at room temperature $\left(22-25^{\circ} \mathrm{C}\right.$ or $27^{\circ} \mathrm{C}$ on the heating plate) with $2 \%$ PFA freshly diluted in PBS, if you plan to perform immunostaining immediately after.

Long fixation: overnight at $+4{ }^{\circ} \mathrm{C}$ with $4 \%$ PFA, freshly diluted in PBS, if you plan to perform immunostaining the following day. If necessary keep the embryos in PFA for up to 1 week-in that case, change the 4\% PFA every 2 days (see Note 14).

3. Prepare in each glass dish a volume of $\sim 500 \mu \mathrm{L}$ PFA, diluted in PBS.

4. With a thin glass manipulation pipette transfer the embryos group by group into the corresponding glass dish, directly from the collection/culture medium into the fixative solution, without rinse step (embryos are known to be very sensitive to environmental changes).

5. Cover the glass dishes with the glass lids; in the case of a long fixation, wrap each dish with parafilm to avoid drying out of the fixative at $4{ }^{\circ} \mathrm{C}$.

6. Incubate in PFA, either $20 \mathrm{~min}$ at room temperature (or $27^{\circ} \mathrm{C}$ on the heating plate) or overnight at $+4{ }^{\circ} \mathrm{C}$.

7. Transfer the embryos with the glass embryo manipulation pipettes from the fixative into PBS:

(a) If PFA incubation was $\leq 30 \mathrm{~min}$, two times $5 \mathrm{~min}$ PBS rinse is enough.

(b) If PFA incubation was longer, wash for at least $30 \mathrm{~min}$ (three times $10 \mathrm{~min}$ ).

In both the cases, and at each further step, embryos have to be aspirated in the pipette with a minimum amount of solution, breathed out (i.e., expelled gently) into the next solution and moved within the glass dish several times (see Note 15).

8. For permeabilization, transfer the embryos and incubate for $30 \mathrm{~min}$ in $0.5 \%$ Triton $\mathrm{X}-100$, freshly diluted in PBS (mix gently to avoid bubbles) (see Note 16).

9. Prepare $2 \mathrm{M} \mathrm{HCl}$ from the stock solution ( $37 \% \mathrm{HCl}$ corresponds to $12 \mathrm{M}$ ) diluted with ultrapure water. Glass dishes containing drops of $2 \mathrm{M} \mathrm{HCl}$ (typically $120 \mu \mathrm{L}$ drops, see Note 17) must be wrapped with parafilm or placed in a humid chamber to prevent drying out of the $\mathrm{HCl}$, and preheated at $37^{\circ} \mathrm{C}$ in the incubator (or oven).

10. For DNA denaturation, transfer the embryos in the preheated $\mathrm{HCl}$ dilution and incubate at $37^{\circ} \mathrm{C}$ for $1 \mathrm{~h}$ (see Note 18).

11. Transfer the embryos into PBS and rinse two times 10 min (see Note 19). 
12. Saturation of nonspecific sites is performed by $1 \mathrm{~h}$ incubation of the embryos in PBS containing 2\% BSA (PBS-BSA 2\%).

13. Dilute the primary antibody directed against $5 \mathrm{mC}$ with PBS containing $2 \%$ BSA in a micro test tube (see Notes 20 and 21). You will need a total of $20 \mu \mathrm{L}$ per group $+20 \mu \mathrm{L}$ for equilibration. In a Petri dish prepare $20 \mu \mathrm{L}$ drops of the primary antibody for each group and add one drop for equilibration. Cover the drops with mineral oil.

14. Embryos are transferred group by group in the primary antibody: first in the equilibration drop and then in their respective antibody incubation drops.

15. Perform incubation in the first antibody overnight at $4{ }^{\circ} \mathrm{C}$.

16. Transfer the embryos in glass dishes with PBS. Wash three times 10 min to remove antibody excess (see Note 22).

17. Perform second antibody incubation: dilute in PBS-BSA 2\% (as above), prepare $20 \mu \mathrm{L}$ drops under mineral oil in a Petri dish and transfer the embryos group by group as above (first in the equilibration drop and then in their respective antibody incubation drops). Incubate for $1 \mathrm{~h}$ at room temperature $\left(22-25^{\circ} \mathrm{C}\right.$ or $27^{\circ} \mathrm{C}$ on the heating plate). From this step to the end, always carefully protect dishes from light, with aluminum foil for example.

18. Transfer the embryos in glass dishes with PBS. Wash three times $10 \mathrm{~min}$ to remove excess antibody (see Note 23).

19. Embryos can be transferred in 2\% PFA (diluted in PBS) for $30 \mathrm{~min}+$ washed once with PBS (2 min) (see Note 24).

20. Transfer the embryos in glass dishes containing a nucleic acid stain diluted in PBS and incubate for $20 \mathrm{~min}$ at $37^{\circ} \mathrm{C}$ (see Note 25).

21. Prepare SuperFrost Plus slides with the identification of the experiment on the side (date/species/embryonic stage/number of embryos and antibody used) and as many areas as groups drawn on the back on the slide with a permanent pen (see Note 26).

22. Load a $100 \mu \mathrm{L}$ pipetman with $40 \mu \mathrm{L}$ of the antifading agent.

23. Aspirate the DNA staining solution to halfway up the glass manipulation pipette and then aspirate the embryos of the first group in a minimum volume of solution (see Note 27).

24. Breath out the embryos in the delimited area of the slide.

25. With a very thin glass pipette aspirate as much solution around the embryos as possible; be particularly careful not to dry the embryos.

26. With the pipetman containing the antifading agent immediately put a little drop of antifading agent on embryos after the removal of the solution.

27. Repeat all the steps for the other groups of embryos.

28. Put a little drop of clear nail polish on each corner of the slide, next to the groups, in order to preserve the $3 \mathrm{D}$ shape of the embryos. 
29. Carefully put the coverslip on the slide and secure with clear nail polish around the coverslip; do not push on the coverslip in order to avoid squashing.

30. Keep the slides at $4{ }^{\circ} \mathrm{C}$ until observation.

Fig. 2

Immunodetection of $5 \mathrm{mC}$ in embryos. Mouse (upper panels) and bovine (lower panels) 1-cell embryos (left column) and blastocysts (right column) after immunostaining for $5 \mathrm{mC}$ using the 33D3 clone (1:500 dilution). Permeabilization was performed for $30 \mathrm{~min}$ (mouse) or $1 \mathrm{~h}$ (bovine) in $0.5 \%$ Triton X100; HCl denaturation was performed with $2 \mathrm{M} \mathrm{HCl}$ for $1 \mathrm{~h}$ either at $37^{\circ} \mathrm{C}$ (mouse) or at room temperature (bovine); and incubation with the primary antibody was performed overnight at $4{ }^{\circ} \mathrm{C}$. Scale bar: $10 \mu \mathrm{m}$ for 1-cell embryos and $20 \mu \mathrm{m}$ for blastocysts

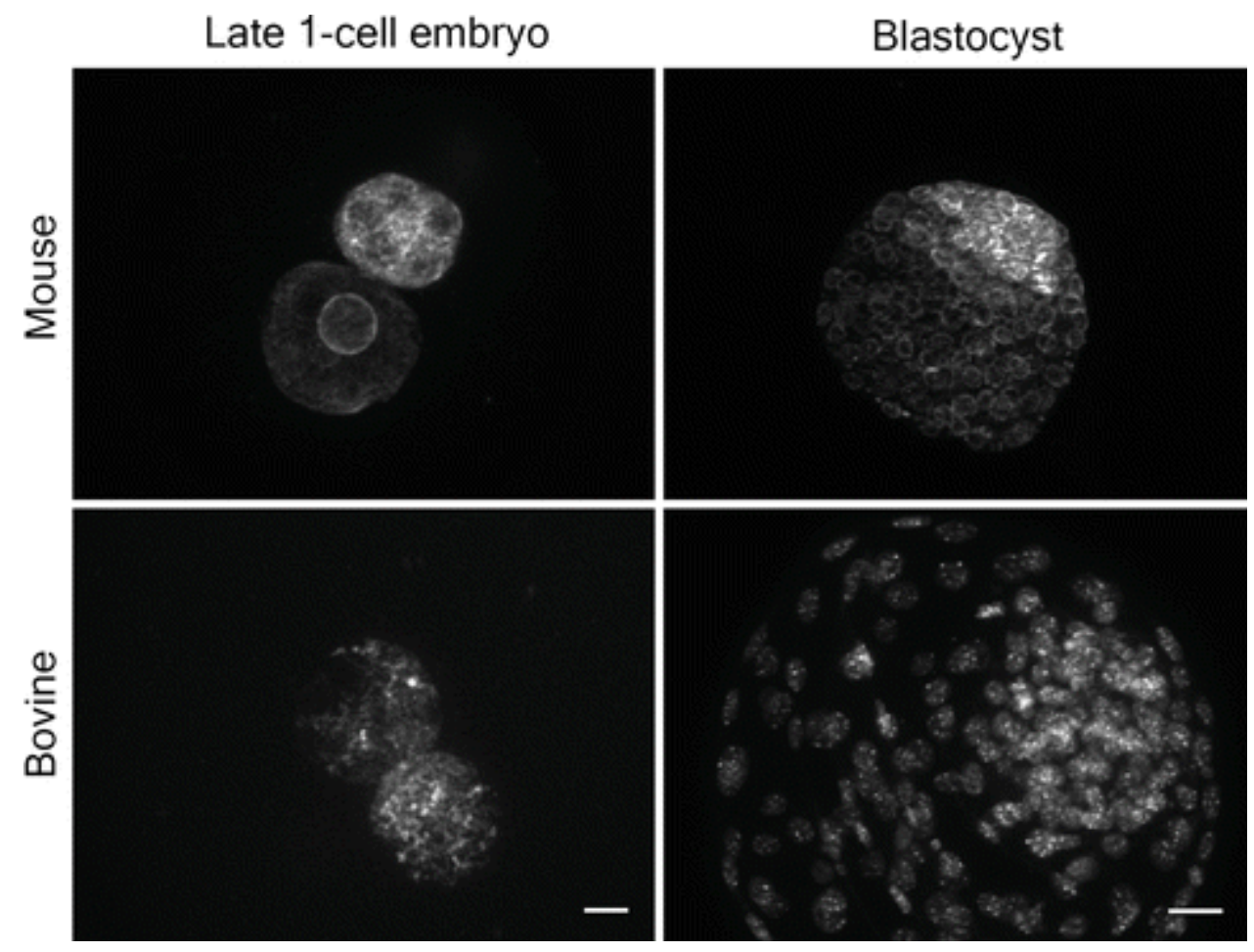




\section{Notes}

1. Primary antibodies recognizing specific antigens can be raised in various species (mouse, rabbit, rat, human autoantibodies) as mentioned in Subheading 1 . The dilution of the primary antibody should be determined in preliminary experiments to find the lowest concentration that still provides an immunostaining signal with a good signal-to-noise ratio. We recommend the use of mouse monoclonal $5 \mathrm{mC}$ antibody clone 33D3 and rabbit polyclonal 5hmC antibody.

2. Primary antibodies can be directly coupled to fluorophores, but in order to amplify the signal, in most cases fluorescently tagged secondary antibodies are used (indirect immunostaining). The range of available fluorophores (such as FITC, Rhodamine, Alexa Fluor) allows for flexibility. If you want to use several antibodies simultaneously, make sure that (1) primary antibodies were produced in different species, (2) each corresponding secondary antibody is coupled to a different fluorophore, and (3) each chosen fluorophore can be distinguished by the microscope that will be used. We recommend "green" Alexa Fluor conjugated IgG that is easier to observe with red or blue DNA counterstaining. Secondary antibodies are diluted according to the manufacturer's recommendations; we commonly use 1/200-1/300 dilutions with antibodies from Jackson ImmunoResearch or Molecular Probes.

3. We recommend the use of mountant with a high refractive index and antifade properties, such as Prolong Gold from Molecular Probes.

4. The thickness of the cover slip is crucially important for high-resolution microscopy. Most microscope objectives are designed for use with No. 1 cover slips $(0.13-0.17 \mathrm{~mm}$ thickness). Use of cover slips that deviate from $0.17 \mathrm{~mm}$ thickness (including mountant) will result in spherical aberration and a reduction in resolution and image intensity. If the cells are grown directly on cover slips, No. 1.5 (0.16-0.19 mm thickness) provides the optimal distance and ease of handling.

5. An extensive assortment of nucleic acid stains is commercially available for DNA counterstaining of the embryos. Their fluorescence absorption and emission spectra span the visible-light spectrum from blue to near-infrared, making them compatible with many different types of secondary antibodies. We often use Propidium Iodide (red fluorescence) or Ethidium Homodimer 2 (red fluorescence), which bind to DNA even after $\mathrm{HCl}$ denaturation in embryos. Alternatively, we use a single-strand DNA antibody, which requires strong protocol adjustments (see Note 25).

6. Ideally room temperature should be stable, between 22 and $25^{\circ} \mathrm{C}$, otherwise we recommend using a heating block set to $27^{\circ} \mathrm{C}$.

7. Aspirator tubes can be hand-made with clear HPLC tubing (diameter $2 \mathrm{~mm}$ ), but are also commercially available (e.g., from Sigma-Aldrich). To this system you can add a filter tip and aspirate by mouth, or add a 1 or $2 \mathrm{~mL}$ syringe to control the valve manually. To manufacture glass pipettes for the manipulation of embryos, stretch a glass capillary (or tip of a Pasteur pipette) in the flame in order to produce very thin pipettes with diameters to fit the embryo. It is easier to work with quite short pipettes (not more than $8 \mathrm{~cm}$ in total), which are a little oblique. 
8. Immunostaining is usually performed in commercially available glass dishes with one or several wells. Plastic 4-cell plates can also be used but are usually less convenient for small preimplantation embryos. The capacity of each well has to be $\geq 500 \mu \mathrm{L}$.

9. Glass cover slips are commercially available in a variety of widths, lengths, and thicknesses (see also Note 4). We recommend square or rectangular cover slips that are more easily placed on the embryos, measuring $22 \times 22 \mathrm{~mm}$ up to $22 \times 40 \mathrm{~mm}$.

10. Cells for microscopy are best grown on collagen-coated cover slips to reduce the distance to the objective for high-resolution imaging. Chamber slides are a more expensive option and most are designed to let the cells grow on the carrier slide, resulting in a longer optical path through mountant.

11. Standard controls for the immunostaining procedure may include: a "no primary antibody" control to assess secondary antibody nonspecific binding; a "no antibody" control to assess tissue autofluorescence; a "normal serum" control to assess IgG nonspecific binding; single label controls for double staining experiments to assess spectral bleed-through and antibody interference; ssDNA primary antibody control and DAPI counterstaining to assess DNA denaturation.

12. Check that the solution has not evaporated to a level that might expose the sections to drying; add more solution if necessary.

13. The $\mathrm{HCl}$ denaturation step is ineffective on cryosections that are adhered to dry-coated microscope slides. This is not an issue for whole mount tissues or thick sections that are kept submerged in a hydrated state, which should be processed using the embryo protocol. Cryosections on microscope slides are denatured in a Schieferdecker type jar olding the slides submerged sideways in the microwave. Metal slide holders require a heat resistant beaker heated on a hotplate.

14. A comparative experiment with a short and a long fixation in parallel, using the same antibodies, should be performed to confirm that a long fixation step does not alter the immunostaining.

15. The overall success of the immunostaining, especially the quality of the signal, depends on the perfect contact of the embryos with each incubation solution. It is thus necessary at each step to correctly transfer the embryos and move them regularly in the glass dish.

16. In some cases, especially in other species than mouse: should the immunodetection not produce a good signal, permeabilization may be either (1) extended to $1 \mathrm{~h}$, (2) performed with $1 \%$ Triton X-100, (3) performed at higher temperature, e.g., $37^{\circ} \mathrm{C}$ or performed, (4) after the removal of the zona pellucida by $\mathrm{HCl}$ or pronase treatments.

17. Transfer of embryos in $2 \mathrm{M} \mathrm{HCl}$ results in an osmotic shock. As a result, the embryos tend to float in the $\mathrm{HCl}$. The use of small drops makes it easier to gather the embryos and bring them back to the bottom of the dish. We therefore recommend the use of smaller glass dishes, or glass plates with several wells, and drops of around $100 \mu \mathrm{L}$. A second consequence of the osmotic shock is the reduction of embryo size, which may necessitate a change of the glass pipette used to transfer them.

18. This denaturation step is required to increase DNA accessibility to the primary $5 \mathrm{mC}$ antibodies. Two concentrations of $\mathrm{HCl}$ are found in the literature: 2 and $4 \mathrm{M}$. Similarly, different incubation times 
(from $10 \mathrm{~min}$ to $1 \mathrm{~h}$ ) and temperatures (room temperature or $37^{\circ} \mathrm{C}$ ) can be found. $4 \mathrm{M} \mathrm{HCl}$ is more often used at room temperature with shorter incubation times (10-20 min), while $2 \mathrm{M} \mathrm{HCl}$ is used with longer incubation times and/or higher temperature. In our experience, temperature is the most sensitive parameter, which is why when using room temperature, we recommend using the heating block for more reproducibility. It is also for this reason that we prefer using the conditions outlined in the main article $\left(2 \mathrm{M} \mathrm{HCl}, 1 \mathrm{~h}, 37^{\circ} \mathrm{C}\right)$. In addition, those conditions work best for the combination with the DNA staining using the single-stranded DNA antibody (see Note 25).

19. An additional step to neutralize the $\mathrm{HCl}$ is often added here. Different neutralization solutions can be used: $0.1 \mathrm{M}$ Tris- $\mathrm{HCl}$, pH 8 or $0.1 \mathrm{M}$ Sodium Borate $\left(\mathrm{Na}_{2} \mathrm{~B}_{4} \mathrm{O}_{7}\right)$, pH 8.5 for $10 \mathrm{~min}$ at room temperature. This step is essential when working with cells, as not all the $\mathrm{HCl}$ can be efficiently and rapidly removed, but is optional with embryos.

20. You may combine several primary antibodies if they are not derived from the same species (to avoid cross-reactivity upon addition of the secondary antibodies). However, the combined use of a $5 \mathrm{mC}$ antibody and an antibody detecting another modified form of cytosine ( $5 \mathrm{hmC}, 5 \mathrm{fC}, 5 \mathrm{caC})$ should be very carefully tested, especially if the aim of the experiments is to quantify the signals. Indeed, in our experiments on mouse embryos, using both anti-5mC and anti-5hmC resulted in a weaker signal for both antibodies [18].

21. Antibodies have to be prepared in sterile conditions, either under an appropriate hood or next to a flame. For the $5 \mathrm{mC}$ antibody clone 33D3 from Eurogentec we recommend 1:500 dilution. If the immunostaining results are not satisfactory, showing too much background or large fluorescent antibody aggregates, we recommend centrifuging the antibody $(10 \mathrm{~min}$ at $11500 \times \mathrm{g}$ with a microcentrifuge) after the dilution, before taking the supernatant to prepare the drops.

22. Tween $20(0.05 \%)$ may be added in these washing steps in order to reduce the background signal if necessary.

23. The "post-fixation" is used to preserve the immunostaining when immediate observation on the microscope is not possible.

24. DNA stain concentrations: $0.002 \mathrm{mM}$ Ethidium Homodimer-2; $1 \mu \mathrm{g} / \mathrm{mL}$ Propidium Iodide.

25. While Ethidium Homodimer-2 and Propidium Iodide can be used for counterstaining in most cases, we could not obtain a reproducible staining with those dyes in mouse 1-cell embryos. We therefore used a single-stranded DNA antibody, which requires additional steps in the protocol. After step 8 of Subheading 3.4, (1) post-fix in 4\% PFA for 25 min at RT; (2) block the nonspecific sites with PBS $/ 0.05 \%$ Tween $/ 4 \%$ low fat milk for $4 \mathrm{~h}$ at RT; (3) incubate with the anti-single-stranded DNA antibody diluted at $1: 10$ in PBS/ $0.05 \%$ Tween $/ 4 \%$ low fat milk for around $40 \mathrm{~h}$ (overnight is not sufficient as it results in great variability of the signal obtained, at least two nights yield good results); (4) repeat step 8 of Subheading 3.4 and continue with the rest of the protocol. As the $5 \mathrm{mC}$ antibody we recommend is mouse IgG and the anti-single-stranded DNA we used is mouse IgM, secondary antibodies 
need to be chosen carefully to avoid cross-reactions.

26. Do not use the extremity of the slide: when using an inverted microscope for observations the objective could be damaged.

27. Each step has to be performed carefully in order to preserve the 3D-shape of the samples. If the group contains many embryos, we recommend taking five embryos at a time.

\section{Acknowledgments}

We thank Tatiana Chebotareva, Cristina Aguilar, and other members of the S.P lab for their help in developing some of the protocols presented, and we thank Richard Meehan for helpful suggestions. All present and past members from N. B's lab are acknowledged for their work and contributions, especially Claire Boulesteix. We wish to acknowledge the Niveleau lab for their development of the original $5 \mathrm{mC}$ antibody and some of the protocols outlined in this chapter. N.A.A.H. is a recipient of a MARA (Malaysia) scholarship; work in S.P.'s lab is supported by the BBSRC and the BHF. Work in N.B.'s lab is supported by the REVIVE Labex.

\section{References}

1. Bird A (2002) DNA methylation patterns and epigenetic memory. Genes Dev 16:6-21

2. Reddington JP, Pennings S, Meehan RR (2013) Non-canonical functions of the DNA methylome in gene regulation. Biochem J 451:13-23

3. Rothbart SB, Strahl BD (2014) Interpreting the language of histone and DNA modifications. Biochim Biophys Acta 1839:627-643

4. Politz JC, Scalzo D, Groudine M (2013) Something silent this way forms: the functional organization of the repressive nuclear compartment. Annu Rev Cell Dev Biol 29:241-270

5. Meehan RR, Dunican DS, Ruzov A et al (2005) Epigenetic silencing in embryogenesis. Exp Cell Res 309:241-249

6. Beaujean N (2014) Histone post-translational modifications in preimplantation mouse embryos and their role in nuclear architecture. Mol Reprod Dev 81:100-112

7. Wongtawan T, Taylor JE, Lawson KA et al (2011) Histone H4K20me3 and HP1 $\alpha$ are late heterochromatin markers in development, but present in undifferentiated embryonic stem cells. J Cell Sci 124:1878-1890

8. Wu H, Zhang Y (2014) Reversing DNA methylation: mechanisms, genomics, and biological functions. Cell 156:45-68

9. Ficz G, Branco MR, Seisenberger S et al (2011) Dynamic regulation of 5-hydroxymethylcytosine in mouse ES cells and during differentiation. Nature 473:398-402

10. Shen L, Zhang Y (2013) 5-Hydroxymethylcytosine: generation, fate, and genomic distribution. Curr Opin Cell Biol 25:289-296 
11. Nestor CE, Ottaviano R, Reinhardt D et al (2015) Rapid reprogramming of epigenetic and transcriptional profiles in mammalian culture systems. Genome Biol 16:11

12. Booth MJ, Ost TW, Beraldi D et al (2013) Oxidative bisulfite sequencing of 5-methylcytosine and 5-hydroxymethylcytosine. Nat Protoc 8:1841-1851

13. Nestor C, Ruzov A, Meehan R et al (2010) Enzymatic approaches and bisulfite sequencing cannot distinguish between 5-methylcytosine and 5-hydroxymethylcytosine in DNA. BioTechniques 48:317319

14. Reynaud C, Bruno C, Boullanger P et al (1992) Monitoring of urinary excretion of modified nucleosides in cancer patients using a set of six monoclonal antibodies. Cancer Lett 61:255-262

15. Barbin A, Montpellier C, Kokalj-Vokac N et al (1994) New sites of methylcytosine-rich DNA detected on metaphase chromosomes. Hum Genet 94:684-692

16. Piyathilake C, Niveleau A, Grizzle W (2004) Role of global methylation of DNA in lung carcinoma (Ch. 10). In: Hayat MA (ed) Immunohistochemistry and in situ hybridization of human carcinomas. Elsevier Acad. Press, Burlington, MA, pp 181-187

17. Keshet I, Schlesinger Y, Farkash S et al (2006) Evidence for an instructive mechanism of de novo methylation in cancer cells. Nat Genet 38:149-153

18. Salvaing J, Aguirre-Lavin T, Boulesteix $\mathrm{C}$ et al (2012) 5-Methylcytosine and 5hydroxymethylcytosine spatiotemporal profiles in the mouse zygote. PLoS One 7:e38156

19. Wu H, D'Alessio AC, Ito $\mathrm{S}$ et al (2011) Genome-wide analysis of 5-hydroxymethylcytosine distribution reveals its dual function in transcriptional regulation in mouse embryonic stem cells. Genes Dev 25:679-684

20. Thomson JP, Lempiäinen H, Hackett JA et al (2012) Non-genotoxic carcinogen exposure induces defined changes in the 5-hydroxymethylome. Genome Biol 13:R93

21. Inoue A, Shen L, Dai Q et al (2011) Generation and replication-dependent dilution of $5 \mathrm{fC}$ and $5 \mathrm{caC}$ during mouse preimplantation development. Cell Res 21:1670-1676

22. Jin SG, Jiang Y, Qiu R et al (2011) 5-Hydroxymethylcytosine is strongly depleted in human cancers but its levels do not correlate with IDH1 mutations. Cancer Res 71:7360-7365

23. Li Y, O'Neill C (2013) 5'-Methylcytosine and 5'-hydroxymethylcytosine each provide epigenetic information to the mouse zygote. PLoS One 8:e63689

24. Salvaing J, Li Y, Beaujean N, O’Neill C (2014) Determinants of valid measurements of global changes in 5'-methylcytosine and 5'-hydroxymethylcytosine by immunolocalisation in the early embryo. Reprod Fertil Dev 27:755-764 